interaction of Lennard-Jones type will aceount for the equation of state and the distribution function of liquid argon with good accuracy, although there is now clear evidence both that the Lennard-Jones shape of interaction function is wrong and that three-body effects are significant, these two errors nearly cancelling at liquid densities.

It is always useful to have the findings of a series of papers available in book form. This book is well printed and produced, though it is pricey. For the above reasons, I can give no worthwhile opinion on how much of the material will ultimately survive. One can only quote from the authors' preface: "Detailed justification of the model of significant strueture theory from first principles is difficult".

H. N. V. Temperley

\section{CLASSICAL ELECTRODYNAMICS}

Electrodynamics of Particles and Plasmas

By P. C. Clemmow and J. P. Dougherty. (AddisonWesley Series in Advanced Physics.) Pp. ix +457. (Addison-Wesloy: London, September 1969.) $163 \mathrm{~s}$.

'THIs book may conveniently be divided into two sections. Chapters one to four are concerned with the behaviour of a point charge in an electromagnetic field. The field caused by a moving charge is investigated by the conventional Lienard-Weichert potential theory and also by Fourier analysis. Cerenkov and gyro radiation are discussed and the dynamical motion of a charged particle in various fields is analysed. Finally, the self-force of a particle caused by its own electromagnetic field is considered. The remainder of the work is concerned with the study of plasmas. This is dealt with from two basic points of view-magneto-ionic theory and kinetic theory derived from the Boltzmann equation.

The propagation of electromagnetic waves in the plasma is, of course, the subject of the first treatment. Standard results are derived, the effect of partial pressures for both ions and electrons is included and the existence of Landau damping is demonstrated. 'The analysis then turns to plasma streams and results derived are verified by the consideration of a Lorentz transformation to the frame moving with the plasma. The two-strcam instability is also discussed.

The collisionless Boltzmann (or Vlasov) equation is derived initially in an intuitive manner and its solution obtained in terms of the invariants of the particle orbits in a given field. Using the Vlasov equation, the propagation of electromagnetic waves is reconsidered, including effects eaused by the thermal spread in particlo velocities. The initial value problem of Landau is developed, as is also the "Landau prescription" for evaluation of integrals. The situation of a plasma in an elcctrostatic field is fully dealt with and this is extended to the case of an external magnetic field using the method of integration along unperturbed orbits. The authors then give a brief treatment of the effects of collisions and discuss microinstabilities including a very clear description of the use of Nyquist diagrams and the Penrose criterion for instability.

In the closing chapters, the authors discuss the transition to magnetohydrodynamic behaviour using, among other techniques, the adiabatic approximation for a collision dominated gas. The book ends with a more rigorous approach to kinotic equations for plasmas.

Throughout, the book is very clear and thought provoking, and it should be an invaluable grounding for a graduate student wishing to procced to research in somo aspect of plasma physics. Indeed, the book may be taken as the starting point for a specialized study, because references aro given to the standard works on the topics dealt with in each chapter, and there are valuable exercises to illustrate the principles discussed. The text does not, however, give a detailed study of magnetohydrodynamics for which, as the authors remark, many excellent references are available.

Apart from certain standard mathematical techniques, nothing is assumed, and all quantities are defined on their introduction. The one exception to this is the quantities $Y_{0}, Z_{0}$, the vacuum admittance and impedance which, although subsequently defined, appear mysteriously on pages 38 and 48 respectively.

This is altogether an excellent text which should be on the shelves of all those who wish to take the study of classical electrodynamics beyond undergraduate level.

David A. DunnetT

\section{WAVES ROUND THE EARTH}

\section{Propagation of Waves}

By P. David and J. Voge. Translated by J. B. Arthur. Pp. $\mathrm{x}+329+4$ plates. (Pergamon: Oxford, London and New York, July 1969.) 85s; \$11.

THE title of this book is a little misleading. The book is not a general discussion of the propagation of all types of waves, but it is a discussion of the very specialized subject of the propagation of radio waves around the Earth. This is an extremely complicated problem, because it depends on so many factors, each one of which is frequency dependent. After a brief introduction to electromagnetic waves, the authors discuss lucidly the effect on radio propagation of the curvature of the Earth, irregularities and obstacles on the surface of the Earth, the troposphere, the ionosphere and various types of interference signals, and the results are usually presented graphically. The case of the propagation of radio signals around the Earth is then considered as a generalization of these discussions and again the results are usually presented in graphical form for various frequency ranges. The book should prove extremely useful to communication engineers, particularly if they are familiar with Maxwell's equations.

W. G. V. ROSSER

\section{BOUNDARY VALUE PROBLEMS}

\section{Boundary Value Problems in Physics and Engineering} By Frank Chorlton. Pp. 250. (Van Nostrand: London, July 1969.) 70s.

The study of boundary value problems in the theory of partial differential equations occupies a central part in the mathematical training of scientists and engineers. Any new publication in this field is therefore bound to excite interest in those charged with the responsibility of providing courses of lectures to students in these disciplines. This book will prove to be a disappointment to them. It has nothing new to offer, and what it does offer has bcen treated in a much better fashion in recent books in this field.

The author covers familiar ground. He states (largely without any proof) the elementary properties of Bessel and Legendre functions and Fourier and Laplace transforms and their application in the solution of elementary boundary value problems. These are just the topies which have to be covered in a first course; what would be expocted of an author is that he should develop at least some of the material in an original fashion. A reader will look in vain for any such originality in this book, and can only be astonished by the author's hope that "the attempt to include within the same covers so many different topics that are not readily found elsewhere may appeal to both lecturer and student".

Such a claim makes me seriously doubt if the author is sufficiently acquainted with the literature of the subject. In commenting on the contents of chapter five, for instance, the author suggests that the methods ovolved by 